Article

\title{
Biological Evaluation and Docking Studies of New Carbamate, Thiocarbamate, and Hydrazide Analogues of Acyl Homoserine Lactones as Vibrio fischeri-Quorum Sensing Modulators
}

\author{
Qiang Zhang, Yves Queneau *(i) and Laurent Soulère * \\ Univ Lyon, Université Claude Bernard Lyon 1, INSA Lyon, CPE Lyon, UMR 5246, CNRS, ICBMS, Institut de \\ Chimie et de Biochimie Moléculaires et Supramoléculaires, Chimie Organique et Bioorganique, Bât. E. Lederer, 1 \\ rue Victor Grignard, F-69622 Villeurbanne, France; qiang.zhang@insa-lyon.fr \\ * Correspondence: yves.queneau@insa-lyon.fr (Y.Q.); laurent.soulere@insa-lyon.fr (L.S.)
}

Received: 30 January 2020; Accepted: 11 March 2020; Published: 15 March 2020

check for updates

\begin{abstract}
A series of carbamate, thiocarbamate, and hydrazide analogues of acylhomoserine lactones (AHLs) were synthesized and their ability to modulate Vibrio fischeri-quorum sensing was evaluated. The compounds in the series exhibit variable side chain length and the possible presence of a diversely substituted phenyl substituent. Biological evaluation on the Vibrio fischeri quorum sensing system revealed that the ethyl substituted carbamate (1) display a weak agonistic activity whereas compounds with longer chain length or benzyl substituents display significant antagonistic activity. The most active compounds in the series were the 4-nitrobenzyl carbamate and thiocarbamate 7 and 11 which exhibited an $\mathrm{IC}_{50}$ value of about $20 \mu \mathrm{M}$. These activities are in the range of other reported of AHL-structurally related quorum sensing (QS) inhibitors. Docking experiments conducted on the LuxR model showed that, compared to the natural ligand OHHL, the additional heteroatom of the carbamate group induces a new hydrogen bond with Tyr70 leading to a different global hydrogen-bond network. Tyr70 is an important residue in the binding site and is strictly conserved in the LuxR family. For the 4-nitrobenzyl carbamate and thiocarbamate analogues, the docking results highlight an additional hydrogen bond between the nitro group and Lys178. For hydrazide analogues, which are deprived of any activity, docking shows that the orientation of the carbonyl group is opposite as compared with the natural ligand, leading to the absence of a H-bond between the $\mathrm{C}=\mathrm{O}$ with Tyr62. This suggests that, either this later interaction, or the influence of the $\mathrm{C}=\mathrm{O}$ orientation on the overall ligand conformation, are essential for the biological activity.
\end{abstract}

Keywords: carbamate analogues; modulators; quorum sensing; docking

\section{Introduction}

Acylhomoserine lactones (AHLs) are molecular signals used by Gram negative bacteria to communicate. They are biosynthesized by proteins of the LuxI family and are recognized by their cognate transcriptional regulators belonging to the LuxR family. This system referred to as quorum sensing (QS) allows bacteria to coordinate their behaviors according to their environment [1-5]. The production of AHLs monitors the regulation of genes encoding for different phenotypes such as biofilm formation, bioluminescence, and virulence. QS can thus be modulated by small AHLs analogues [3,6-12]. To date, we reported the synthesis and QS activity of several AHLs analogues in which the amide function was replaced by bioisosteric functions such as urea [13,14], sulfonamide [15], reverse amide [16], and heterocycles [17]. Carbamates and thiocarbamates have been extensively used as bioisosteric analogues of amide bioactive compounds, as mentioned by Ghosh and Brindisi [18]. 
Although, a comprehensive study of this type of compounds in the field of QS modulation is missing, since to our knowledge, only one example has been described in the literature with a hexyl substituted carbamate as TraR modulator [19]. Building on our work on Vibrio fischeri-quorum sensing modulation using urea-type AHLs analogues [13], we report here the synthesis, the biological evaluation, and docking studies of carbamate (eight compounds) and thiocarbamate (three compounds) AHL analogues for which the urea additional NH group is replaced by an oxygen or a sulfur atom (Figure 1). We also described three hydrazide analogues of AHLs for which the urea functional group has been inverted as shown in Figure 1.

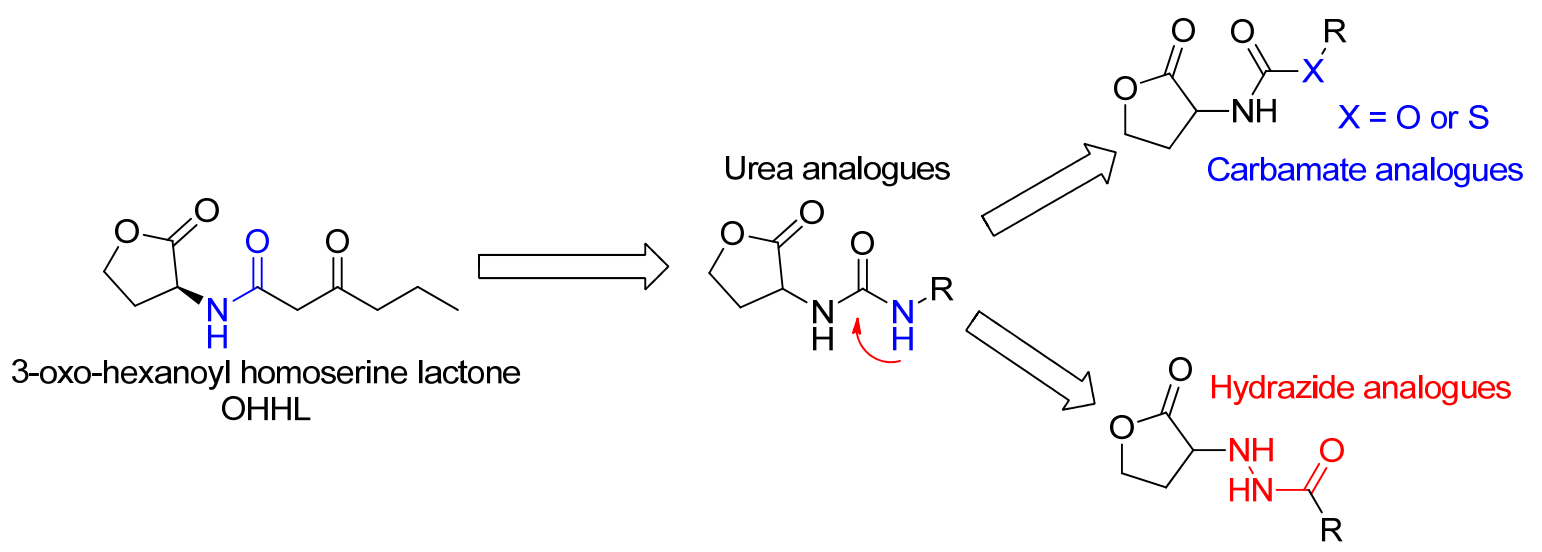

Figure 1. Design of analogues of OHHL modified on the amide functional group.

\section{Materials and Methods}

\subsection{Synthesis}

All commercial materials were used without further purification. Flash chromatography was carried out using Macherey-Nagel (Hoerdt, France) Kieselgel $60 \mathrm{M}$ silica. Analytical thin layer chromatography was realized using aluminum-backed plates coated with Macherey-Nagel Kieselgel 60 XtraSIL G/UV254. Compounds were visualized under UV light (at $254 \mathrm{~nm}$ ) or stained using $\mathrm{KMnO}_{4}$. Nuclear magnetic resonance (NMR) spectra were recorded on a Bruker AVL300 or a Bruker AV400 or a Bruker AV500 spectrometer (Billerica, MA, USA), operating respectively at 300, 400, and $500 \mathrm{MHz}$ for the proton $\left({ }^{1} \mathrm{H}\right)$ NMR. Carbon $\left({ }^{13} \mathrm{C}\right)$ NMR spectra were recorded on a Bruker AVL300 or a Bruker AV400 spectrophotometer or a Bruker AV500 spectrometer, operating, respectively, at 75, 100, and $125 \mathrm{MHz}$. Chemical shifts were reported in parts per million (ppm) in the scale relative to residual solvent signals. Multiplicities are abbreviated as follows: s, singlet; $d$, doublet; $t$, triplet; dd, doublet of doublets; dt, doublet of triplts, m, multiplet; br, broad. Coupling constants were measured in Hertz $(\mathrm{Hz})$. High-resolution mass spectra (HRMS) and low-resolution mass spectra were performed by the Centre Commun de Spectrométrie de Masse (CCSM), University of Lyon 1, Lyon, France. L- or D-homoserine lactone hydrobromide was synthesized as previously described [20].

\subsubsection{General Procedure for Route A}

To a solution of L- $\alpha$-amino- $\gamma$-butyrolactone hydrobromide $(100 \mathrm{mg}, 0.55 \mathrm{mmol})$ in anhydrous THF ( $2 \mathrm{~mL}) \mathrm{N}, \mathrm{N}$-diisopropylethylamine $(0.213 \mathrm{~mL}, 0.66 \mathrm{mmol})$ at $0{ }^{\circ} \mathrm{C}$ was added, and the appropriate commercially available benzyl chloroformate or ethyl chloroformate (1.2 eq) was added dropwise. The mixture was stirred overnight while the temperature was warmed up to room temperature. The mixture was then diluted with EtOAc $(10 \mathrm{~mL})$ and washed with brine $(10 \mathrm{~mL})$. The organic phase was collected, dried over anhydrous $\mathrm{Na}_{2} \mathrm{SO}_{4}$, concentrated, and the residue was purified by flash chromatography to give compounds $\mathbf{1}$ and $\mathbf{5}$ as white solids.

$\mathrm{N}$-(ethoxycarbonyl)-L-homoserine lactone (1). Flash chromatography of the crude product (1:1 EtOAc-pentane) afforded $1(72 \%)$ as a white solid. IR $\left(\mathrm{cm}^{-1}\right): 3332(\mathrm{~N}-\mathrm{H}), 1785(\mathrm{C}=\mathrm{O}$, lactone $), 1679$ 
(C=O, carbamate), 1537 (-NHCO-). $[\alpha]_{\mathrm{D}}^{24}=-43.9(\mathrm{c}=0.34$, acetone). NMR data were consistent with the literature [21].

$\mathrm{N}$-(benzyloxycarbonyl)-L-homoserine lactone (5). Flash chromatography of the crude product (1:3 EtOAc-pentane) afforded $5(48 \%)$ as a white solid. IR $\left(\mathrm{cm}^{-1}\right): 3324(\mathrm{~N}-\mathrm{H}), 1776(\mathrm{C}=\mathrm{O}$, lactone), 1686 (C=O, carbamate), 1539 (-NHCO-). $[\alpha]_{\mathrm{D}}^{24}=-27.9$ ( $\mathrm{c}=0.29$, acetone). NMR data were consistent with the literature [22].

$\mathrm{N}$-(4-nitrobenzylthiocarbonyl)-L-homoserine lactone (11). To a solution of triphosgene (1 mmol) in DCM (2 mL) 4-nitro benzylmercaptan ( $2.4 \mathrm{mmol})$ was added slowly which was dissolved in DCM (2 $\mathrm{mL})$ at $0{ }^{\circ} \mathrm{C}$, followed by addition of pyridine $(0.2 \mathrm{~mL}, 2.48 \mathrm{mmol})$ dissolved in DCM $(2 \mathrm{~mL})$. After stirring for $2 \mathrm{~h}$ at $0{ }^{\circ} \mathrm{C}$, the reaction was quenched by addition of water $(2 \mathrm{~mL})$. The reaction mixture was diluted with DCM $(16 \mathrm{~mL})$ and washed with ice-cold water $(8 \mathrm{~mL})$. The organic layer was dried over anhydrous $\mathrm{Na}_{2} \mathrm{SO}_{4}$, concentrated to afford the S-4-nitrobenzyl chlorothioformate (390 mg, yield 70\%) as a colorless oil, used immediately without further purification. ${ }^{1} \mathrm{H}$ NMR $(300 \mathrm{MHz}$, Chloroform- $d$ ) $\delta 8.21(\mathrm{~d}, J=8.9 \mathrm{~Hz}, 2 \mathrm{H}, \mathrm{Ph}), 7.51(\mathrm{~d}, J=8.7 \mathrm{~Hz}, 2 \mathrm{H}, \mathrm{Ph}), 4.22\left(\mathrm{~s}, 2 \mathrm{H}, \mathrm{CH}_{2}\right)$. Following the general procedure for the route $\mathbf{A}$, flash chromatography of the crude product (1:1 EtOAc-pentane) afforded $11(51 \%)$ as a white solid. IR $\left(\mathrm{cm}^{-1}\right): 3307(\mathrm{~N}-\mathrm{H}), 1782(\mathrm{C}=\mathrm{O}$, lactone), $1640(\mathrm{C}=\mathrm{O}$, thiocarbamate), $1513(-\mathrm{NHCO}-), 1491\left(\mathrm{Ar}-\mathrm{NO}_{2}\right), 1345\left(\mathrm{Ar}-\mathrm{NO}_{2}\right) .[\alpha]_{\mathrm{D}}^{24}=-30.4\left(\mathrm{c}=0.09\right.$, acetone). ${ }^{1} \mathrm{H}$ NMR $(300 \mathrm{MHz}$, Chloroform-d) $\delta 8.15(\mathrm{~d}, J=8.8 \mathrm{~Hz}, 2 \mathrm{H}, \mathrm{Ph}), 7.49(\mathrm{~d}, J=8.7 \mathrm{~Hz}, 2 \mathrm{H}, \mathrm{Ph}), 6.24(\mathrm{~d}, J=6.0 \mathrm{~Hz}, 1 \mathrm{H}$, $\mathrm{NH}), 4.57(\mathrm{~m}, 1 \mathrm{H}, \mathrm{CH}), 4.46$ (m, 1H, OCHH-lactone), 4.27 (m, 1H, OCHH-lactone), $4.19\left(\mathrm{~s}, 2 \mathrm{H}, \mathrm{SCH}_{2}\right)$, $2.79\left(\mathrm{~m}, 1 \mathrm{H}, \mathrm{CH}\right.$-lactone), 2.22 (m, 1H, CHH-lactone). ${ }^{13} \mathrm{C} \mathrm{NMR}(75 \mathrm{MHz}$, Chloroform- $d) \delta 174.8$ (CO-lactone), 167.1 (SCONH), 147.1 (Ph), 145.8 (Ph), 129.7 (2C, Ph), 123.8 (2C, Ph), 66.0 ( $\mathrm{OCH}_{2}$-lactone), $50.8(\mathrm{CH}-\mathrm{NH}), 33.4\left(\mathrm{SCH}_{2}\right), 30.1\left(\mathrm{CH}_{2}\right.$-lactone). ESI-HRMS $(\mathrm{M}+\mathrm{Na})^{+}$: 319.0359; found: 319.0355.

\subsubsection{General Procedure for Route B}

Carbamates: (i) To a stirred solution of different alcohols (1.05 eq) in THF, triethylamine (2.3 eq) and $p$-nitrophenyl chloroformate $(1 \mathrm{eq})$ at $0{ }^{\circ} \mathrm{C}$ were added. The reaction mixture was allowed to warm up to room temperature and was stirred overnight. The mixture was then diluted with EtOAc (20 $\mathrm{mL})$ and filtered. The solution was washed with brine $(2 \times 10 \mathrm{~mL})$; the organic phase was collected, dried over anhydrous $\mathrm{Na}_{2} \mathrm{SO}_{4}$, concentrated to afford the desired carbonates. (ii) To a solution of $\mathrm{L}$ - $\alpha$-amino- $\gamma$-butyrolactone hydrobromide ( $1 \mathrm{eq})$ in dry THF $(2 \mathrm{~mL})$, triethylamine ( 1 eq) and various $p$-nitrophenyl carbonates $(1.2 \mathrm{eq})$ dissolved in THF $(1 \mathrm{~mL})$ were added at room temperature. The reaction mixture was stirred at $40{ }^{\circ} \mathrm{C}$ overnight. The solution was filtered and the solvent was evaporated. The residue was purified by flash chromatography to give the corresponding carbamates as white solids.

Thiocarbamates: (i) To a solution of different thiols $(1 \mathrm{eq})$ in dry DCM, triethylamine $(1.05$ eq), 4-dimethylaminopyridine (DMAP) (1.05 eq), and $p$-nitrophenyl chloroformate (1.05 eq) at $0{ }^{\circ} \mathrm{C}$ were added, respectively. The reaction mixture was allowed to warm up to room temperature and stirred overnight. The mixture was diluted with DCM $(20 \mathrm{~mL})$ and washed with water $(2 \times 10 \mathrm{~mL})$, the organic phase was collected, dried over anhydrous $\mathrm{Na}_{2} \mathrm{SO}_{4}$, concentrated, and purified by flash chromatography to get the desired thiocarbonate. (ii) To a solution of $\mathrm{L}-\alpha$-amino- $\gamma$-butyrolactone hydrobromide (1 eq) in dry THF ( $2 \mathrm{~mL}$ ), triethylamine (1 eq or $1.2 \mathrm{eq})$ and $p$-nitrophenyl thiocarbonates (1.2 eq) dissolved in THF $(1 \mathrm{~mL})$ at room temperature were added. The reaction mixture was then stirred at $60{ }^{\circ} \mathrm{C}$ overnight. The reaction mixture was cooled to room temperature, filtered, and the solvent was evaporated. The residue was purified by flash chromatography to give the corresponding thiocarbamates as white solids.

$N$-(butoxycarbonyl)-L-homoserine lactone (2). From butyl alcohol the Butyl 4-nitrophenyl carbonate was obtained (48\%) as a yellow liquid. ${ }^{1} \mathrm{H}$ NMR $(300 \mathrm{MHz}$, Chloroform- $d) \delta 8.18(\mathrm{~d}, J=9.2 \mathrm{~Hz}, 2 \mathrm{H}$, $\mathrm{Ph}), 7.30(\mathrm{~d}, J=9.2 \mathrm{~Hz}, 2 \mathrm{H}, \mathrm{Ph}), 4.21\left(\mathrm{t}, J=6.6 \mathrm{~Hz}, 2 \mathrm{H}, \mathrm{OCH}_{2}\right), 1.80-1.56\left(\mathrm{~m}, 2 \mathrm{H}, \mathrm{CH}_{2}\right), 1.44-1.26(\mathrm{~m}$, $\left.2 \mathrm{H}, \mathrm{CH}_{2}\right), 0.89\left(\mathrm{t}, J=7.4 \mathrm{~Hz}, 3 \mathrm{H}, \mathrm{CH}_{3}\right)$. According to the general procedure $\mathrm{B}$, flash chromatography 
of the crude product (1:2 EtOAc-pentane) afforded $2(68 \%)$ as a white solid. IR $\left(\mathrm{cm}^{-1}\right): 3333(\mathrm{~N}-\mathrm{H})$, 1775 (C=O, lactone), 1688 (C=O, carbamate), 1537 (-NHCO-). $[\alpha]_{\mathrm{D}}^{24}=-30\left(\mathrm{c}=0.44\right.$, acetone). ${ }^{1} \mathrm{H}$ NMR (500 MHz, Chloroform- $d$ ) $\delta 5.39$ (s, 1H, NH), 4.56-4.33 (m, 2H, OCHH-lactone, CH), $4.24(\mathrm{~m}, 1 \mathrm{H}$, OCHH-lactone), $4.07\left(\mathrm{t}, J=6.7 \mathrm{~Hz}, 2 \mathrm{H}, \mathrm{OCH}_{2}\right), 2.73(\mathrm{~m}, 1 \mathrm{H}, \mathrm{CH}$-lactone), 2.21 (m, 1H, CHH-lactone), $1.59\left(\mathrm{~m}, 2 \mathrm{H}, \mathrm{CH}_{2}\right), 1.36\left(\mathrm{~m}, 2 \mathrm{H}, \mathrm{CH}_{2}\right), 0.91\left(\mathrm{t}, J=7.4 \mathrm{~Hz}, 3 \mathrm{H}, \mathrm{CH}_{3}\right) .{ }^{13} \mathrm{C} \mathrm{NMR}(126 \mathrm{MHz}$, Chloroform- $d$ ) $\delta 175.2$ (CO-lactone), $156.5(\mathrm{OCONH}), 65.8\left(\mathrm{OCH}_{2}\right.$-lactone), $65.5\left(\mathrm{OCH}_{2}\right), 50.4(\mathrm{CH}-\mathrm{NH}), 30.9\left(\mathrm{CH}_{2}\right)$, $30.3\left(\mathrm{CH}_{2}\right.$-lactone), $19.0\left(\mathrm{CH}_{2}\right), 13.7\left(\mathrm{CH}_{3}\right)$. ESI-HRMS $(\mathrm{M}+\mathrm{Na})^{+}: 224.0893$; found: 224.0892.

N-(butoxycarbonyl)-D-homoserine lactone (3). Compound 3 was obtained from Butyl 4-nitrophenyl carbonate and $\mathrm{D}-\alpha$-amino- $\gamma$-butyrolactone hydrobromide. Flash chromatography of the crude product (1:3 EtOAc-pentane) afforded $3(74 \%)$ as a white solid. IR $\left(\mathrm{cm}^{-1}\right): 3329(\mathrm{~N}-\mathrm{H}), 1775(\mathrm{C}=\mathrm{O}$, lactone), 1687 (C=O, carbamate), 1536 (-NHCO-). $[\alpha]_{\mathrm{D}}^{24}=+35.3\left(\mathrm{c}=0.4\right.$, acetone). ${ }^{1} \mathrm{H}$ NMR $(500 \mathrm{MHz}$, Chloroform- $d$ ) $\delta 5.49(\mathrm{~d}, J=6.5 \mathrm{~Hz}, 1 \mathrm{H}, \mathrm{NH}), 4.40(\mathrm{~m}, 2 \mathrm{H}, \mathrm{OCHH}$-lactone, $\mathrm{CH}), 4.22(\mathrm{~m}, 1 \mathrm{H}, \mathrm{OCHH}$-lactone), 4.05 $\left(\mathrm{t}, J=6.8 \mathrm{~Hz}, 2 \mathrm{H}, \mathrm{OCH}_{2}\right), 2.69\left(\mathrm{~m}, 1 \mathrm{H}, \mathrm{CHH}\right.$-lactone), 2.21 (m, 1H, CHH-lactone), $1.57\left(\mathrm{~m}, 2 \mathrm{H}, \mathrm{CH}_{2}\right)$, 1.40-1.24 (m, 2H, CH $\left.\mathbf{C H}_{2}\right), 0.94-0.84\left(\mathrm{t}, J=7.3 \mathrm{~Hz}, 3 \mathrm{H}, \mathrm{CH}_{3}\right) .{ }^{13} \mathrm{C}$ NMR $(126 \mathrm{MHz}$, Chloroform-d) $\delta 175.4$ (CO-lactone), $156.6(\mathrm{OCONH}), 65.8\left(\mathrm{OCH}_{2}\right.$-lactone), $65.5\left(\mathrm{OCH}_{2}\right), 50.4(\mathrm{CH}-\mathrm{NH}), 31.0\left(\mathrm{CH}_{2}\right), 30.1$ $\left(\mathrm{CH}_{2}\right.$-lactone), $19.1\left(\mathrm{CH}_{2}\right), 13.7\left(\mathrm{CH}_{3}\right)$. ESI-HRMS $(\mathrm{M}+\mathrm{Na})^{+}$: 224.0893; found: 224.0897.

N-(hexyloxycarbonyl)-L-homoserine lactone (4). From hexyl alcohol Hexyl 4-nitrophenyl carbonate was obtained (56\%) as a yellow liquid. ${ }^{1} \mathrm{H}$ NMR $(300 \mathrm{MHz}$, Chloroform- $d) \delta 8.25(\mathrm{~d}, J=9.2 \mathrm{~Hz}, 2 \mathrm{H}, \mathrm{Ph})$, $7.36(\mathrm{~d}, J=9.2 \mathrm{~Hz}, 2 \mathrm{H}, \mathrm{Ph}), 4.27\left(\mathrm{t}, J=6.7 \mathrm{~Hz}, 2 \mathrm{H}, \mathrm{OCH}_{2}\right), 1.83-1.61\left(\mathrm{~m}, 2 \mathrm{H}, \mathrm{CH}_{2}\right), 1.51-1.19(\mathrm{~m}, 6 \mathrm{H}, 3$ $\left.\times \mathrm{CH}_{2}\right), 0.89\left(\mathrm{t}, J=6.6 \mathrm{~Hz}, 3 \mathrm{H}, \mathrm{CH}_{3}\right)$. According to the general procedure $\mathrm{B}$, flash chromatography of the crude product (1:2 EtOAc-pentane) afforded $4(63 \%)$ as a white solid. IR $\left(\mathrm{cm}^{-1}\right): 3332(\mathrm{~N}-\mathrm{H})$, $1775\left(\mathrm{C}=\mathrm{O}\right.$, lactone), $1688\left(\mathrm{C}=\mathrm{O}\right.$, carbamate), 1539 (-NHCO-). $[\alpha]_{\mathrm{D}}^{24}=-26.9$ (c = 0.35, acetone). ${ }^{1} \mathrm{H}$ NMR (500 MHz, Chloroform- $d$ ) $\delta 5.40$ (s, 1H, NH), 4.41 (m, 2H, OCHH-lactone, CH), $4.24(\mathrm{~m}, 1 \mathrm{H}$, OCHH-lactone), $4.05\left(\mathrm{t}, J=6.7 \mathrm{~Hz}, 2 \mathrm{H}, \mathrm{OCH} \mathbf{H}_{2}\right), 2.72(\mathrm{~m}, 1 \mathrm{H}, \mathrm{CHH}$-lactone), 2.21 (m, 1H, CHH-lactone), $1.59\left(\mathrm{~m}, 2 \mathrm{H}, \mathrm{CH}_{2}\right), 1.43-1.19\left(\mathrm{~m}, 6 \mathrm{H}, \mathrm{CH}_{2} \mathrm{CH}_{2} \mathrm{CH}_{2}\right), 0.86\left(\mathrm{t}, J=6.6 \mathrm{~Hz}, 3 \mathrm{H}, \mathrm{CH}_{3}\right) .{ }^{13} \mathrm{C} \mathrm{NMR}(126 \mathrm{MHz}$, Chloroform- $d$ ) $\delta 175.2$ (CO-lactone), $156.5(\mathrm{OCONH}), 65.8\left(\mathrm{OCH}_{2}\right.$-lactone), $65.8\left(\mathrm{OCH}_{2}\right), 50.4(\mathrm{CH}-\mathrm{NH})$, $31.4\left(\mathrm{CH}_{2}\right), 30.3\left(\mathrm{CH}_{2}\right.$-lactone), $28.8\left(\mathrm{CH}_{2}\right), 25.5\left(\mathrm{CH}_{2}\right), 22.5\left(\mathrm{CH}_{2}\right), 14.0\left(\mathrm{CH}_{3}\right)$. ESI-HRMS $(\mathrm{M}+\mathrm{Na})^{+}$: 252.1206; found: 252.1207 .

N-(4-bromobenzyloxycarbonyl)-L-homoserine lactone (6). From 4-bromobenzyl alcohol (4-Bromoophenyl)methyl 4-nitrophenyl carbonate was obtained by flash chromatography of the crude product (1:8 EtOAc-pentane) in $47 \%$ yield as a white solid. IR $\left(\mathrm{cm}^{-1}\right): 3306(\mathrm{~N}-\mathrm{H}), 1776(\mathrm{C}=\mathrm{O}$, lactone), 1695 (C=O, carbamate), 1538 (-NHCO-). $[\alpha]_{\mathrm{D}}^{24}=-23.5$ (c = 0.19, acetone). ${ }^{1} \mathrm{H}$ NMR (300 MHz, Chloroform- $d$ ) $\delta 8.27$ (d, J = 9.2 Hz, 2H, Ph), $7.54(\mathrm{~d}, J=8.4 \mathrm{~Hz}, 2 \mathrm{H}, \mathrm{Ph}), 7.43-7.28(\mathrm{~m}, 4 \mathrm{H}, \mathrm{Ph}), 5.24(\mathrm{~s}$, 2H, OCH $\mathrm{H}_{2} \mathrm{Ar}$ ). ${ }^{13} \mathrm{C}$ NMR (76 MHz, Chloroform-d) $\delta 155.4$ (OCO), $152.4(\mathrm{Ph}), 145.5(\mathrm{Ph}), 133.2(\mathrm{Ph}), 132.0$ (2C, Ph), $130.3(2 \mathrm{C}, \mathrm{Ph}), 125.3(2 \mathrm{C}, \mathrm{Ph}), 123.3(\mathrm{Ph}), 121.8(2 \mathrm{C}, \mathrm{Ph}), 70.1\left(\mathrm{OCH}_{2} \mathrm{Ar}\right)$. ESI-HRMS (M + Na) $)^{+}$: 373.9635; found: 373.9637 . According to the general procedure B, flash chromatography of the crude product (1:3 EtOAc-pentane) afforded $6(40 \%)$ as a white solid. ${ }^{1} \mathrm{H}$ NMR $(400 \mathrm{MHz}$, Chloroform- $d$ ) $\delta$ $7.48(\mathrm{~d}, J=8.4 \mathrm{~Hz}, 2 \mathrm{H}, \mathrm{Ph}), 7.22(\mathrm{~d}, J=8.4 \mathrm{~Hz}, 2 \mathrm{H}, \mathrm{Ph}), 5.39(\mathrm{~s}, 1 \mathrm{H}, \mathrm{NH}), 5.07\left(\mathrm{~s}, 2 \mathrm{H}, \mathrm{OCH}_{2} \mathrm{Ar}\right), 4.42(\mathrm{~m}$, 2H, OCHH-lactone, $\mathrm{CH}), 4.25$ (m, 1H, OCHH-lactone), 2.88-2.66 (m, 1H, CHH-lactone), $2.21(\mathrm{~m}, 1 \mathrm{H}$, CHH-lactone). ${ }^{13} \mathrm{C}$ NMR (101 MHz, Chloroform- $d$ ) $\delta 174.9$ (CO-lactone), 156.0 (OCONH), 134.9 (Ph), 131.7 (2C, Ph), 129.8 (2C, Ph), 122.37 (Ph), $66.5\left(\mathrm{OCH}_{2} \mathrm{Ar}\right), 65.8$ ( $\mathrm{OCH}_{2}$-lactone), 50.5 (CH-NH), 30.4 $\left(\mathrm{CH}_{2}\right.$-lactone). ESI-HRMS $(\mathrm{M}+\mathrm{Na})^{+}: 335.9842$; found: 335.9843 .

$N$-(4-nitrobenzyloxycarbonyl)-L-homoserine lactone (7). From 4-nitrobenzyl alcohol (4-Nitrophenyl)methyl 4-nitrophenyl carbonate was obtained in $78 \%$ yield as a yellow solid. ${ }^{1} \mathrm{H}$ NMR data were consistent with the literature [23]. According to the general procedure $\mathrm{B}$, flash chromatography of the crude product (1:1 EtOAc-pentane) afforded $7(52 \%)$ as a white solid. IR 
$\left(\mathrm{cm}^{-1}\right)$ : 3339 (N-H), 1783 (C=O, lactone), 1692 (C=O, carbamate), 1533 (-NHCO-), $1512\left(\mathrm{Ar}-\mathrm{NO}_{2}\right), 1345$ $\left(\mathrm{Ar}-\mathrm{NO}_{2}\right) \cdot[\alpha]_{\mathrm{D}}^{24}=-24.5(\mathrm{c}=0.45$, acetone). NMR data were consistent with the literature [24].

$N$-(4-phenylbutoxycarbonyl)-L-homoserine lactone (8). From 4-phenyl butanol, flash chromatography of the crude product (1:8 EtOAc-pentane) afforded (4-Phenyl)butyl 4-nitrophenyl carbonate $(48 \%)$ as a white solid. ${ }^{1} \mathrm{H}$ NMR $(300 \mathrm{MHz}$, Chloroform- $d) \delta 8.24(\mathrm{~d}, J=8.4 \mathrm{~Hz}, 2 \mathrm{H}, \mathrm{Ph}), 7.34$ $(\mathrm{d}, J=8.4 \mathrm{~Hz}, 2 \mathrm{H}, \mathrm{Ph}), 7.32-7.11(\mathrm{~m}, 5 \mathrm{H}, \mathrm{Ph}), 4.29\left(\mathrm{t}, J=6.0 \mathrm{~Hz}, 2 \mathrm{H}, \mathrm{OCH}_{2}\right), 2.67\left(\mathrm{t}, J=6.9 \mathrm{~Hz}, 2 \mathrm{H}, \mathrm{CH}_{2}\right)$, 1.94-1.68 (m, 4H, $\left.\mathrm{CH}_{2} \mathrm{CH}_{2}\right) .{ }^{13} \mathrm{C}$ NMR (76 MHz, Chloroform-d) $\delta 155.6(\mathrm{OCO}), 152.6(\mathrm{Ph}), 145.4(\mathrm{Ph})$, $141.7(\mathrm{Ph}), 128.5$ (2C, Ph), 128.4 (2C, Ph), 126.0 (Ph), 125.3 (2C, Ph), 121.9 (2C, Ph), $69.4\left(\mathrm{OCH}_{2}\right), 35.4$ $\left(\mathrm{CH}_{2}\right), 28.1\left(\mathrm{CH}_{2}\right), 27.5\left(\mathrm{CH}_{2}\right)$. ESI-HRMS $(\mathrm{M}+\mathrm{Na})^{+}$: 338.0999; found: 338.0999. Following general procedure $\mathrm{B}$, flash chromatography of the crude product (1:2 EtOAc-pentane) afforded $8(40 \%)$ as a white solid. IR $\left(\mathrm{cm}^{-1}\right)$ : $3336(\mathrm{~N}-\mathrm{H}), 1776(\mathrm{C}=\mathrm{O}$, lactone), 1687 (C=O, carbamate), 1537 (-NHCO-). $[\alpha]_{\mathrm{D}}^{24}=-17.4\left(\mathrm{c}=0.13\right.$, acetone). ${ }^{1} \mathrm{H}$ NMR $(500 \mathrm{MHz}$, Chloroform- $d$ ) $\delta 7.33-7.23(\mathrm{~m}, 2 \mathrm{H}, \mathrm{Ph}), 7.22-7.12$ (m, 3H, Ph), 5.25 (d, J = 12.3 Hz, 1H, NH), 4.41 (m, OCHH-lactone, $\mathrm{CH}), 4.25$ (m, 1H, OCHH-lactone), $4.12\left(\mathrm{t}, J=6.2 \mathrm{~Hz}, 2 \mathrm{H}, \mathrm{OCH}_{2}\right), 2.77\left(\mathrm{~m}, 1 \mathrm{H}, \mathrm{CHH}\right.$-lactone), $2.64\left(\mathrm{t}, J=7.1 \mathrm{~Hz}, 2 \mathrm{H}, \mathrm{CH}_{2} \mathrm{Ph}\right), 2.20(\mathrm{~m}$, $1 \mathrm{H}, \mathrm{CHH}$-lactone), $1.69\left(\mathrm{~m}, 4 \mathrm{H}, \mathrm{CH}_{2} \mathrm{CH}_{2}\right) .{ }^{13} \mathrm{C} \mathrm{NMR}\left(126 \mathrm{MHz}, \mathrm{CDCl}_{3}\right) \delta 175.1$ (CO-lactone), 156.4 (OCONH), $142.1(\mathrm{Ph}), 128.5(2 \mathrm{C}, \mathrm{Ph}), 128.4(2 \mathrm{C}, \mathrm{Ph}), 125.9(\mathrm{Ph}), 65.9\left(\mathrm{OCH}_{2}\right.$-lactone), $65.6\left(\mathrm{OCH}_{2}\right), 50.5$ (CH-NH), $35.5\left(\mathrm{CH}_{2}\right), 30.6\left(\mathrm{CH}_{2}\right.$-lactone), $28.5\left(\mathrm{CH}_{2}\right), 27.7\left(\mathrm{CH}_{2}\right)$. ESI-HRMS $(\mathrm{M}+\mathrm{Na})^{+}: 300.1206$; found: 300.1210 .

$N$-(butylthiocarbonyl)-L-homoserine lactone (9). From butyl mercaptan, flash chromatography of the crude product (1:10 EtOAc-pentane) afforded Butyl 4-nitrophenyl thiocarbonate $(62 \%)$ as a light yellow liquid. ${ }^{1} \mathrm{H}$ NMR $(300 \mathrm{MHz}$, Chloroform- $d$ ) $\delta 8.27(\mathrm{~d}, J=9.2 \mathrm{~Hz}, 2 \mathrm{H}, \mathrm{Ph}), 7.35(\mathrm{~d}, J=9.2 \mathrm{~Hz}$, 2H, Ph), $2.96\left(\mathrm{t}, J=7.3 \mathrm{~Hz}, 2 \mathrm{H}, \mathrm{SCH}_{2}\right), 1.82-1.63\left(\mathrm{~m}, 2 \mathrm{H}, \mathrm{CH}_{2}\right), 1.53-1.33\left(\mathrm{~m}, 2 \mathrm{H}, \mathrm{CH}_{2}\right), 0.95(\mathrm{t}$, $\left.J=7.3 \mathrm{~Hz}, 3 \mathrm{H}, \mathrm{CH}_{3}\right) .{ }^{13} \mathrm{C}$ NMR $(76 \mathrm{MHz}$, Chloroform- $d$ ) $\delta 169.77$ (SCO), $155.65(\mathrm{Ph}), 145.33(\mathrm{Ph}), 125.29$ (2C, Ph), $122.06(2 \mathrm{C}, \mathrm{Ph}), 31.46\left(\mathrm{CH}_{2}\right), 31.20\left(\mathrm{CH}_{2}\right), 21.81\left(\mathrm{CH}_{2}\right), 13.54\left(\mathrm{CH}_{3}\right)$. ESI-HRMS $(\mathrm{M}+\mathrm{Na})^{+}$: 278.0457; found: 278.0462. Following general procedure $B$, flash chromatography of the crude product (1:3 EtOAc-pentane) afforded $9(46 \%)$ as a white solid. IR $\left(\mathrm{cm}^{-1}\right): 3315(\mathrm{~N}-\mathrm{H}), 1775(\mathrm{C}=\mathrm{O}$, lactone), $1643\left(\mathrm{C}=\mathrm{O}\right.$, thiocarbamate), $1522(-\mathrm{NHCO}-) .[\alpha]_{\mathrm{D}}^{24}=-13.4\left(\mathrm{c}=0.17\right.$, acetone). ${ }^{1} \mathrm{H}$ NMR $(300 \mathrm{MHz}$, Chloroform- $d$ ) $\delta 6.12(\mathrm{~d}, J=5.9 \mathrm{~Hz}, 1 \mathrm{H}, \mathrm{NH}), 4.56(\mathrm{~m}, 1 \mathrm{H}, \mathrm{CH}), 4.50-4.37(\mathrm{~m}, 1 \mathrm{H}, \mathrm{OCHH}$-lactone), $4.27\left(\mathrm{~m}, 1 \mathrm{H}, \mathrm{OCHH}\right.$-lactone), $2.91\left(\mathrm{t}, J=7.3 \mathrm{~Hz}, 2 \mathrm{H}, \mathrm{SCH}_{2}\right), 2.80(\mathrm{~m}, 1 \mathrm{H}, \mathrm{CH}$-lactone $), 2.22(\mathrm{~m}$, $1 \mathrm{H}, \mathrm{CHH}$-lactone), $1.61\left(\mathrm{~m}, 2 \mathrm{H}, \mathrm{CH}_{2}\right), 1.39\left(\mathrm{~m}, 2 \mathrm{H}, \mathrm{CH}_{2}\right), 0.91\left(\mathrm{t}, J=7.3 \mathrm{~Hz}, 3 \mathrm{H}, \mathrm{CH}_{3}\right) .{ }^{13} \mathrm{C} \mathrm{NMR}$ (76 MHz, Chloroform- $d$ ) $\delta 175.0$ (CO-lactone), 168.9 (SCONH), $66.0\left(\mathrm{OCH}_{2}\right.$-lactone), $50.6(\mathrm{CH}-\mathrm{NH})$, $32.2\left(\mathrm{CH}_{2}\right), 30.4\left(\mathrm{CH}_{2}\right.$-lactone), $29.8\left(\mathrm{SCH}_{2}\right), 21.9\left(\mathrm{CH}_{2}\right), 13.6\left(\mathrm{CH}_{3}\right)$. ESI-HRMS $(\mathrm{M}+\mathrm{Na})^{+}$: 240.0664; found: 240.0653 .

$N$-(benzylthiocarbonyl)-L-homoserine lactone (10). From benzyl mercaptan, flash chromatography of the crude product (1:11 EtOAc-pentane) afforded Benzyl 4-nitrophenyl thiocarbonate (39\%) as a white solid. ${ }^{1} \mathrm{H}$ NMR $(300 \mathrm{MHz}$, Chloroform- $d$ ) $\delta 8.27(\mathrm{~d}, J=9.2 \mathrm{~Hz}, 2 \mathrm{H}, \mathrm{Ph}), 7.43-7.27(\mathrm{~m}, 7 \mathrm{H}, \mathrm{Ph}), 4.20$ (s, 2H, SCH 2$).{ }^{13} \mathrm{C}$ NMR (76 MHz, Chloroform-d) $\delta 169.24$ (SCO), 155.57 (Ph), $145.43(\mathrm{Ph}), 136.15(\mathrm{Ph})$, 128.97 (2C, Ph), 128.85 (2C, Ph), 127.90 (Ph), 125.32 (2C, Ph), 122.07 (2C, Ph), $35.84\left(\mathrm{SCH}_{2} \mathrm{Ph}\right)$. ESI-HRMS $(\mathrm{M}+\mathrm{Na})^{+}: 312.0301$; found: 312.0302 . Following general procedure $\mathrm{B}$, flash chromatography of the crude product (1:3 EtOAc-pentane) afforded $10(27 \%)$ as a white solid. IR $\left(\mathrm{cm}^{-1}\right): 3321(\mathrm{~N}-\mathrm{H}), 1776$ (C=O, lactone), $1661\left(\mathrm{C}=\mathrm{O}\right.$, thiocarbamate), $1518(-\mathrm{NHCO}-) .[\alpha]_{\mathrm{D}}^{24}=-12.6\left(\mathrm{c}=0.11\right.$, acetone). ${ }^{1} \mathrm{H}$ NMR (500 MHz, Chloroform- $d$ ) $\delta$ 7.35-7.26 (m, 4H, Ph), 7.26-7.21 (m, 1H, Ph), $6.12(\mathrm{~s}, 1 \mathrm{H}, \mathrm{NH}), 4.55(\mathrm{~m}$, $1 \mathrm{H}, \mathrm{CH}), 4.44(\mathrm{~m}, 1 \mathrm{H}, \mathrm{OCHH}$-lactone $), 4.25\left(\mathrm{~m}, 1 \mathrm{H}, \mathrm{OCHH}\right.$-lactone), $4.17(\mathrm{~s}, 2 \mathrm{H}, \mathrm{SCH})_{2}, 2.79(\mathrm{~m}, 1 \mathrm{H}$, CHH-lactone), 2.21 (m, 1H, CHH-lactone). ${ }^{13} \mathrm{C}$ NMR (126 MHz, Chloroform- $d$ ) $\delta 174.8$ (CO-lactone), 168.1 (SCONH), 137.6 (Ph), 128.8 (2C, Ph), 128.6 (2C, Ph), 127.4 (Ph), $66.0\left(\mathrm{OCH}_{2}\right.$-lactone), 50.7 (CH-NH), $34.3\left(\mathrm{SCH}_{2} \mathrm{Ph}\right), 30.4\left(\mathrm{CH}_{2}\right.$-lactone). ESI-HRMS $(\mathrm{M}+\mathrm{Na})^{+}: 274.0508$; found: 274.0511. 


\subsubsection{General Procedure for Route C (Hydrazides)}

(i) To a $25 \mathrm{~mL}$ flask, $4 \mathrm{~mL}$ of hydrazine ( $80 \%$ in water) and carboxylic esters $(1 \mathrm{~g})$ were added. The mixture was stirred at $70{ }^{\circ} \mathrm{C}$ for $45 \mathrm{~min}$ and then cooled to room temperature. The reaction mixture was then extracted with EtOAc $(30 \mathrm{~mL})$ and washed with brine $(30 \mathrm{~mL})$. The organic phase was dried over anhydrous $\mathrm{Na}_{2} \mathrm{SO}_{4}$, concentrated, and the residue was purified by flash chromatography to give corresponding hydrazide compounds.

(ii) To a solution of different hydrazides (1.0 eq) in dry DCM, DIEA (2.0 eq), $\alpha$-Bromo- $\gamma$-butyrolactone (2.0 eq), and $\operatorname{TBABr}(0.3 \mathrm{eq})$ were added, respectively. The reaction mixture was stirred at $40^{\circ} \mathrm{C}$ overnight. The solvent was evaporated. The residue was purified by flash chromatography to give the corresponding hydrazide AHL analogues.

N'-(2-oxotetrahydrofuran-3-yl)butyrohydrazide (12). From methyl butanoic ester, Butyrohydrazide was obtained by flash chromatography of the crude product (95:5 EtOAc-MeOH) in $90 \%$ yield. NMR data were consistent with the literature [25]. According to the general procedure $C$, flash chromatography of the crude product (EtOAc) afforded $12(82 \%) . \mathrm{IR}\left(\mathrm{cm}^{-1}\right): 3299(\mathrm{~N}-\mathrm{H}), 1774(\mathrm{C}=\mathrm{O}$, lactone), 1637 (C=O, hydrazide), 1538 (-NHCO-). ${ }^{1} \mathrm{H}$ NMR (300 MHz, Chloroform- $d$ ) $\delta 7.60(\mathrm{~s}, 1 \mathrm{H}, \mathrm{NH})$, $4.40(\mathrm{~m}, 1 \mathrm{H}, \mathrm{OCHH}$ - lactone), 4.21 (m, 1H, OCHH-lactone), $4.12(\mathrm{br}, 1 \mathrm{H}, \mathrm{NH}), 3.91(\mathrm{~m}, 1 \mathrm{H}, \mathrm{CH}-\mathrm{NH})$, $2.48\left(\mathrm{~m}, 1 \mathrm{H}, \mathrm{CHH}\right.$-lactone), 2.29-2.08 (m, 3H, $\mathrm{CHH}$-lactone, $\left.\mathrm{CH}_{2} \mathrm{CO}\right), 1.68\left(\mathrm{~m}, 2 \mathrm{H}, \mathrm{CH}_{2}-\mathrm{CH}_{3}\right), 0.94(\mathrm{t}$, $\left.J=7.4 \mathrm{~Hz}, 3 \mathrm{H}, \mathrm{CH}_{3}\right) .{ }^{13} \mathrm{C} \mathrm{NMR}(101 \mathrm{MHz}$, Chloroform- $d) \delta 176.0(\mathrm{CO}), 173.2(\mathrm{CO}), 65.8\left(\mathrm{OCH}_{2}\right.$-lactone), $57.9(\mathrm{CH}-\mathrm{NH}), 36.3\left(\mathrm{CH}_{2} \mathrm{CO}\right), 27.5\left(\mathrm{CH}_{2}\right.$-lactone $), 18.9\left(\mathrm{CH}_{2} \mathrm{CH}_{3}\right), 13.7\left(\mathrm{CH}_{3}\right)$. ESI-HRMS $(\mathrm{M}+\mathrm{Na})^{+}$: 209.0897; found: 209.0900 .

N'-(2-oxotetrahydrofuran-3-yl)hexanehydrazide (13). From methyl hexanoic ester Hexanehydrazide was obtained by flash chromatography of the crude product (95:5 EtOAc-MeOH) in $74 \%$ yield. NMR data were consistent with the literature [24]. According to the general procedure C, flash chromatography of the crude product (4:1 EtOAc-pentane) afforded $13(48 \%)$. IR $\left(\mathrm{cm}^{-1}\right): 3326(\mathrm{~N}-\mathrm{H})$, 1762 ( $\mathrm{C}=\mathrm{O}$, lactone), 1641 (C=O, hydrazide), 1525 (-NHCO-). ${ }^{1} \mathrm{H}$ NMR (300 MHz, Chloroform- $d$ ) $\delta$ $7.56(\mathrm{~s}, 1 \mathrm{H}, \mathrm{NH}), 4.41$ (m, 1H, OCHH-lactone), 4.22 (m, 1H, OCHH-lactone), 3.93 (m, 1H, CH-NH), 3.84 (br, 1H, NH), 2.49 (m, 1H, CHH-lactone), 2.33-2.09 (m, 3H, CHH-lactone, $\left.\mathrm{CH}_{2} \mathrm{CO}\right), 1.62(\mathrm{~m}$, $\left.2 \mathrm{H}, \mathrm{CH}_{2} \mathrm{CH}_{2} \mathrm{CO}\right), 1.41-1.18\left(\mathrm{~m}, 4 \mathrm{H}, \mathrm{CH}_{2} \mathrm{CH}_{2} \mathrm{CH}_{3}\right), 0.97-0.78\left(\mathrm{~m}, 3 \mathrm{H}, \mathrm{CH}_{3}\right) .{ }^{13} \mathrm{C} \mathrm{NMR}(101 \mathrm{MHz}$, Chloroform- $d) \delta 175.9(\mathrm{CO}), 173.3(\mathrm{CO}), 65.8\left(\mathrm{OCH}_{2}\right.$-lactone), $57.9(\mathrm{CH}-\mathrm{NH}), 34.5\left(\mathrm{CH}_{2} \mathrm{CO}\right), 31.4$ $\left(\mathrm{CH}_{2} \mathrm{CH}_{2} \mathrm{CH}_{3}\right), 27.5\left(\mathrm{CH}_{2}\right.$-lactone $), 25.1\left(\mathrm{CH}_{2} \mathrm{CH}_{2} \mathrm{CH}_{2} \mathrm{CH}_{3}\right), 22.3\left(\mathrm{CH}_{2} \mathrm{CH}_{3}\right), 13.9\left(\mathrm{CH}_{3}\right)$. ESI-HRMS $(\mathrm{M}+\mathrm{H})^{+}$: 215.1390; found: 215.1394 .

N'-(2-oxotetrahydrofuran-3-yl)-4-phenylbutanehydrazide (14). From ethyl 4-phenylbutanoic ester, 4-Phenylbutanehydrazide was obtained as a white solid (96\%). NMR data were consistent with the literature [26]. According to the general procedure $C$, flash chromatography of the crude product (EtOAc) afforded 14 (63\%). IR ( $\left.\mathrm{cm}^{-1}\right)$ : $3235(\mathrm{~N}-\mathrm{H}), 1769$ (C=O, lactone), 1640 (C=O, hydrazide), 1539 (-NHCO-). ${ }^{1} \mathrm{H}$ NMR (400 MHz, Chloroform-d) $\delta 7.57$ (s, 1H, NH), 7.32-7.26 (m, 2H, Ph), 7.22-7.12 (m, $3 \mathrm{H}, \mathrm{Ph}), 4.39$ (m, 1H, OCHH- lactone), 4.20 (m, 1H, OCHH-lactone), $3.89(\mathrm{~m}, 1 \mathrm{H}, \mathrm{CH}-\mathrm{NH}), 3.78$ (br, $1 \mathrm{H}, \mathrm{NH}), 2.65\left(\mathrm{t}, J=7.5 \mathrm{~Hz}, 2 \mathrm{H}, \mathrm{CH}_{2} \mathrm{CO}\right), 2.47$ (m, 1H, CHH-lactone), 2.27-2.13 (m, 3H, CHH-lactone, $\left.\mathrm{CH}_{2} \mathrm{Ph}\right), 2.06-1.88\left(\mathrm{~m}, 2 \mathrm{H}, \mathrm{CH}_{2} \mathrm{CH}_{2} \mathrm{Ph}\right) .{ }^{13} \mathrm{C}$ NMR (101 MHz, Chloroform- $d$ ) $\delta 175.8(\mathrm{CO}), 172.8(\mathrm{CO})$, 141.1 (Ph), $128.5(2 \mathrm{C}, \mathrm{Ph}), 128.5(2 \mathrm{C}, \mathrm{Ph}), 126.1(\mathrm{Ph}), 65.8\left(\mathrm{OCH}_{2}\right.$-lactone), $57.9(\mathrm{CH}-\mathrm{NH}), 35.1\left(\mathrm{CH}_{2} \mathrm{CO}\right)$, $33.7\left(\mathrm{CH}_{2} \mathrm{Ph}\right), 27.5\left(\mathrm{CH}_{2}\right.$-lactone), $26.8\left(\mathrm{CH}_{2} \mathrm{CH}_{2} \mathrm{Ph}\right)$. ESI-HRMS $(\mathrm{M}+\mathrm{Na})^{+}:$285.1210; found: 285.1203.

\subsection{Biological Evaluation}

The recombinant Escherichia coli strain NM522 with the sensor plasmid pSB401 was used to measure the induction of luminescence. Bacterial cultures were grown in Luria broth $(50 \mathrm{~mL})$ at $30^{\circ} \mathrm{C}$. After $18 \mathrm{~h}$, this bacterial culture was diluted 10 times to be used in the assay using 96-well plates (100 $\mu \mathrm{L}$ per well). For agonistic activity, compounds were tested at increasing concentrations in DMSO (max 
$2 \%$ in a total volume of $200 \mu \mathrm{L}$ of LB). For antagonistic activity, compounds were tested in competition with OHHL (200 nM) at increasing concentrations in DMSO (max 2\% in a total volume of $200 \mu \mathrm{L}$ ). This $200 \mathrm{nM}$ concentration of OHHL is fully pertinent since concentrations as low as 10 or $50 \mathrm{nM}$ are already valid protocols as reported in meaningful studies $[27,28]$. Bioluminescence was measured with a Tecan spark luminometer (Männedorf, Switzerland).

\subsection{Molecular Modeling}

Tridimensional structures of compounds were obtained from Chem3D Pro (PerkinElmer, Waltham, MA, USA). The luxR model [29] complexed with OHHL described in a previous study was used for docking studies [30]. The binding site was created by selecting residues in the neighborhood of OHHL [31]. A Docking box $15 \times 15 \times 15 \AA$ center on OHHL was used for docking experiments performed with the genetical algorithm [32] docking engine of the ArgusLab software [33] with default parameters. Hydrogen bonds were assigned with a distance inferior or equal to $3 \AA$. Figure 3 was created using PyMOL.

\section{Results and Discussion}

\subsection{Synthesis}

The synthesis of ethyl (1) and benzyl (5) carbamate analogues (Scheme 1) was achieved using the corresponding commercially available ethyl or benzyl chloroformate in $72 \%$ and $48 \%$ yield, respectively (route A). For compound 11, the S-4-nitrobenzyl chlorothioformate was first prepared using triphosgene and was then reacted with L-homoserine lactone (route A). In other cases, para-nitrophenyl chloroformate was first reacted with various alcohols and thiols to produce activated para-nitrophenyl carbonates or thiocarbonates which were further involved in reaction with L-homoserine lactone or (D-homoserine lactone for compound 3) (route B) [34]. Thus, compounds 2-4 and 6-10 were synthesized in two steps with overall yields ranging from $11 \%$ to $41 \%$. For hydrazide analogues, the reaction of hydrazine with various esters gave the corresponding hydrazides which were used in a nucleophilic substitution reaction with $\alpha$-bromo- $\gamma$-butyrolactone furnishing hydrazides AHLs analogues 12-14 in good yield over two steps.

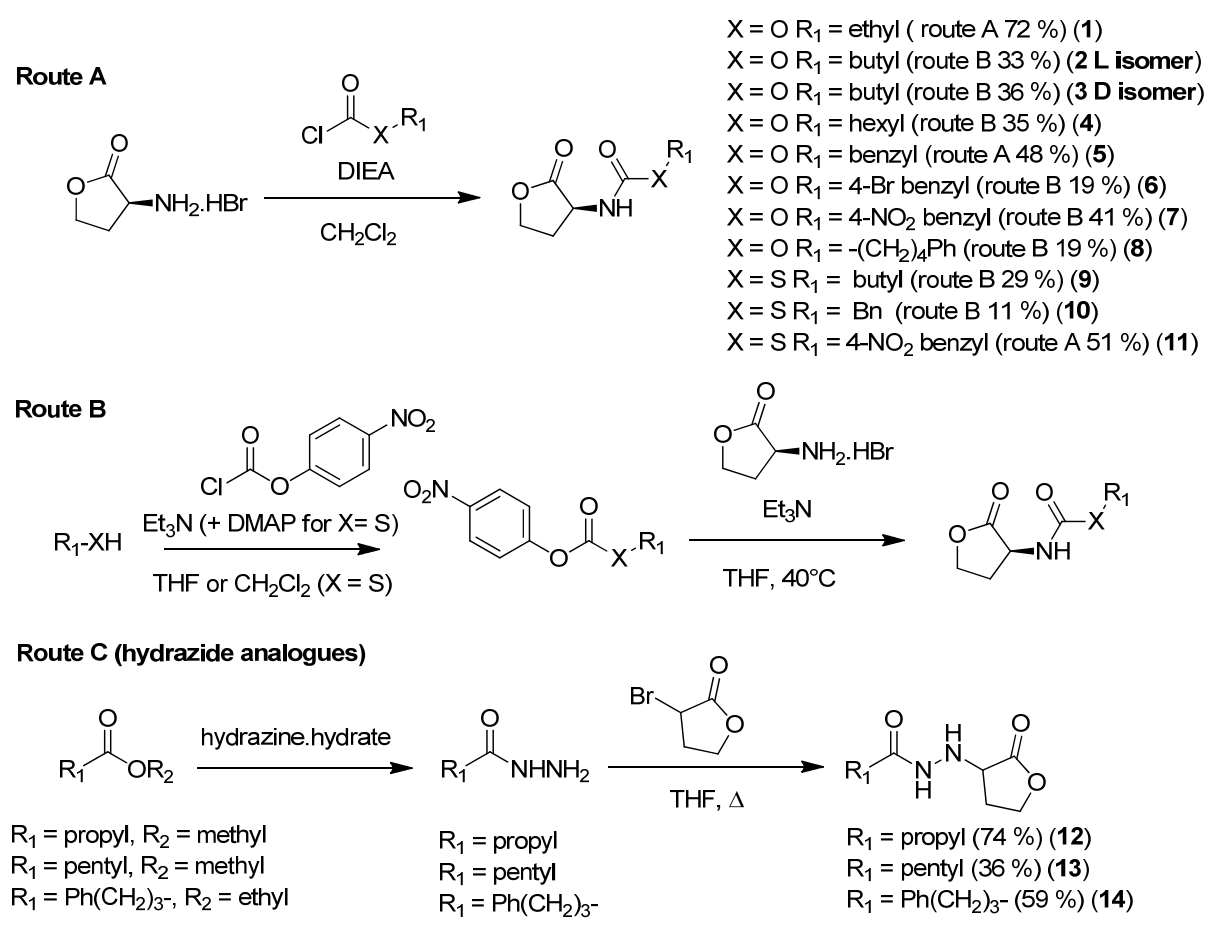

Scheme 1. Synthesis of carbamate, thiocarbamate, and hydrazide analogues of acylhomoserine lactone. 


\subsection{Biological Evaluation}

All compounds were evaluated for the ability to induce bioluminescence (agonistic activity) or to decrease bioluminescence in the presence of 3-oxo-hexanoyl-L-homoserine lactone (OHHL) at $200 \mathrm{nM}$ (antagonistic activity) [35]. Hydrazide AHL analogues were deprived of any activity. Among carbamate analogues, only the ethyl carbamate derivative (1) exhibited very weak agonistic activity by inducing at $200 \mu \mathrm{M} 18 \%$ of the bioluminescence obtained with the natural ligand OHHL at a concentration of $200 \mathrm{nM}$.

A first assessment of the antagonistic activity was performed by measuring residual bioluminescence at $100 \mu \mathrm{M}$ concentration of analogues in competition with $200 \mathrm{nM}$ of OHHL. Compounds 2, 4-7, and 9-11 were found to considerably decrease the bioluminescence (Figure 2). A residual bioluminescence of $42 \%$ for the L-butyl carbamate derivative 2 vs. $89 \%$ for the D-isomer 3 was measured showing the influence of the configuration on luminescence and therefore on QS inhibition [36]. A remaining luminescence of $22 \%$ was observed for the hexyl carbamate analogue 4, the most active among alkyl carbamate analogues. With respect to aromatic analogues, 7, 9, 10, and $\mathbf{1 1}$ were found to be the most active with a residual bioluminescence of about $10 \%$. Interestingly, the thiocarbamates analogues $\mathbf{9}$ and $\mathbf{1 0}$ were found more active than the corresponding oxygenated carbamate analogues $\mathbf{2}$ and 5 .

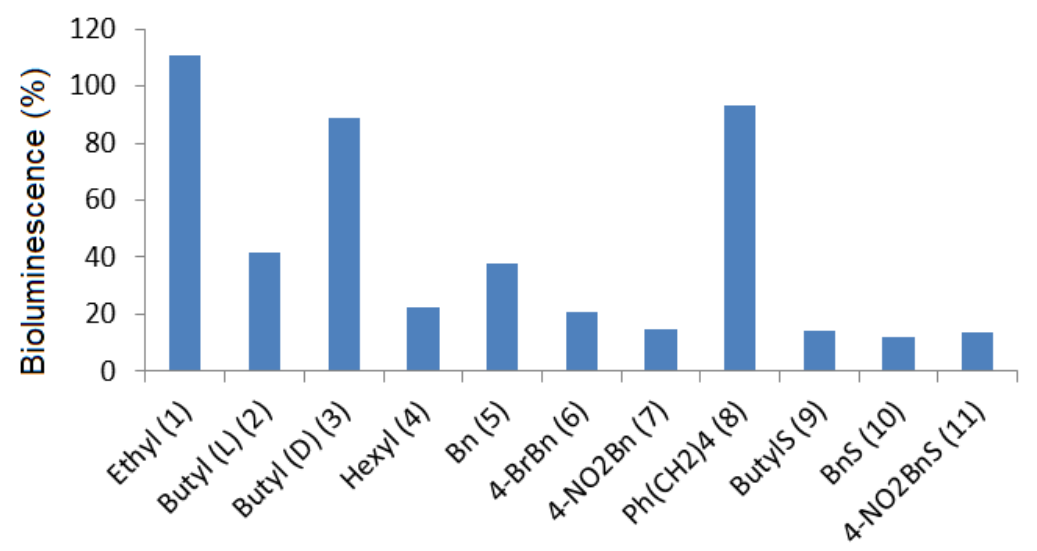

Figure 2. Antagonistic activity of carbamate and thiocarbamate analogues 1-11: residual bioluminescence observed for all compounds at $100 \mu \mathrm{M}$. The luminescence was induced by OHHL at a concentration of $200 \mathrm{nM}$.

To determine $\mathrm{IC}_{50}$ values, the decrease of bioluminescence of was measured using increasing concentration of each compound in presence of $200 \mathrm{nM}$ of OHHL (Table 1). Values ranging from 22 to $94 \mu \mathrm{M}$, in the range of other reported of AHL-structurally related QS inhibitors [3,7,10], were measured for compounds 2, 4-7, and 9-11. Differences in the calculated $\log P$ values are consistent with inhibitory activity for most compounds except 4-nitrobenzyl analogues. This is the case for all thiocarbamates vs. carbamates, and also when comparing the butyl (2) and hexyl (4) derivatives, or the benzyl and 4-bromobenzyl substituents.

The 4-nitrobenzyl derivatives $\mathbf{7}$ and $\mathbf{1 1}$ were identified as the most active compounds in the series with and $\mathrm{IC}_{50}$ value of $22-23 \mu \mathrm{M}$. However, no additive effect of the presence of the nitro group and of the sulfur atom in the thiocarbamate was observed, although $\operatorname{LogP}$ of the 4-nitrobenzyl thiocarbamate is higher than the 4-nitrobenzyl carbamate like for other compounds in the series. For these two compounds, the presence of the 4-nitro substituent is therefore the key point. 
Table 1. Predicted $\log \mathrm{P}$ and $\mathrm{IC}_{50}$ values for compounds $\mathbf{2 , 4 - 7}$, and $\mathbf{9 - 1 1}$. $\mathrm{IC}_{50}$ values were estimated with an increasing concentration of each compound in competition with $200 \mathrm{nM}$ of OHHL.

\begin{tabular}{ccc}
\hline Compounds & Predicted $\log \mathbf{P}$ & IC $_{50}(\mu \mathrm{M})$ \\
\hline Butyl (2) & 0.65 & $94( \pm 1)$ \\
Hexyl (4) & 1.19 & $73( \pm 3)$ \\
Bn (5) & 1.14 & $86( \pm 3)$ \\
4-BrBn (6) & 1.97 & $64( \pm 4)$ \\
4-NO Bn (7) & 0.51 & $22( \pm 3)$ \\
ButylS (9) & 1.22 & $45( \pm 7)$ \\
BnS (10) & 1.71 & $64( \pm 3)$ \\
4-NO N $_{2}$ BnS (11) & 1.17 & $23( \pm 4)$ \\
\hline
\end{tabular}

\subsection{Docking Studies}

In order to gain insight into structure-activity relationships, we performed docking studies for the active compounds using the LuxR model and a genetic algorithm. All compounds were docked as flexible ligands to study their binding modes which are described in the Table 2. Based on the results, all compounds exhibit hydrogens bonds with Trp66 and Asp 79 like the natural ligand OHHL does. For the agonist 1 bearing a small ethyl substituent, a particularly high level of flexibility was observed, leading to a binding mode comparable with the natural ligand in terms of hydrogen bonds network, however with some differences in terms of distances. For longer chain lengths (more hydrophobic compounds $2,4,9$ ), the alkyl chain together with the supplementary oxygen atom of the carbamate function orientate the carbamoyl group towards Tyr70 leading to hydrophobic interactions. A supplementary hydrogen bond with this amino acid is also observed (Figure 3A). The consequence of this particular orientation is that the hydrogen bond which normally exists between the $\mathrm{C}=\mathrm{O}$ of the AHL amide with Tyr62 is not present, due to a distance superior to $3.5 \AA$ between the $\mathrm{C}=\mathrm{O}$ of the carbamate and Tyr62. For compounds bearing an aromatic substituent, the binding mode is globally the same, with attractive interactions and a hydrogen bond with Tyr70. For thiocarbamate derivatives, a difference with their oxygenated homologs was observed with the additional hydrogen bond with Tyr70 [37] but also with a hydrogen bond between the $\mathrm{C}=\mathrm{O}$ of the carbamate group and Tyr62 as for the natural ligand. This interaction, which is not observed for carbamates, may explain the increased activity of thiocarbamate derivatives (except for nitrated compounds). Overall, an additional hydrogen bond with the Tyr70 residue is found for most carbamate/thiocarbamate analogues. The Tyr70 residue, which is a conserved residue in the LuxR proteins family (equivalent to Tyr64 in LasR [38]) is confirmed as particularly important for interactions with AHLs analogues.

Table 2. Occurrence and distances for hydrogen bonds between Trp66, Asp79, Tyr 62, Tyr70, and the main chemical functions of studied compounds with distances $(\AA)$. + indicates a possible H-bond; the function implicated is indicated in brackets.

\begin{tabular}{|c|c|c|c|c|c|}
\hline Compounds & Trp66 & Asp79 & Tyr62 & Tyr70 & Lys178 \\
\hline OHHL (natural ligand) & $+2.34(\mathrm{C}=\mathrm{O}$ lactone $)$ & +3.01 (NH amide) & +3.01 ( $\mathrm{C}=\mathrm{O}$ amide $)$ & - & - \\
\hline Ethyl (1 agonist) & $+2.44(\mathrm{C}=\mathrm{O}$ lactone $)$ & +3.0 ( $\mathrm{NH}$ carbamate) & $+2.91(\mathrm{C}=\mathrm{O}$ carbamate $)$ & - & - \\
\hline Butyl (2) & $+2.20(\mathrm{C}=\mathrm{O}$ lactone $)$ & +2.92 (NH carbamate) & - & +2.97 (O carbamate) & - \\
\hline Bn (5) & +2.89 (C=O lactone $)$ & +2.98 (NH carbamate) & - & +3.01 (O carbamate) & - \\
\hline $4-\operatorname{BrBn}(6)$ & $+2.35(\mathrm{C}=\mathrm{O}$ lactone $)$ & +2.95 (NH carbamate) & $+3.01(\mathrm{C}=\mathrm{O}$ carbamate $)$ & +3.32 (O carbamate) & - \\
\hline $4-\mathrm{NO}_{2} \mathrm{Bn}(7)$ & $+2.07(\mathrm{C}=\mathrm{O}$ lactone $)$ & +2.99 ( NH carbamate) & - & +3.04 (O carbamate) & ++2.22 and $3.05\left(\mathrm{NO}_{2}\right)$ \\
\hline $4-\mathrm{NO}_{2} \mathrm{BnS}(\mathbf{1 1})$ & $+2.12(\mathrm{C}=\mathrm{O}$ lactone $)$ & +3.14 (NH carbamate) & - & +3.25 (S carbamate) & ++1.96 and $3.85\left(\mathrm{NO}_{2}\right)$ \\
\hline Hydrazide (12) & $+2.45(\mathrm{C}=\mathrm{O}$ lactone $)$ & +2.94 (NH hydrazide) & - & $+2.21(\mathrm{C}=\mathrm{O}$ hydrazide $)$ & - \\
\hline
\end{tabular}

For nitro compounds 7 and 11, two additional hydrogen bonds involving the nitro group and the Lys178 residue have been identified (Figure 3B). As these two compounds are the most active in the series, these new interactions appear as a key element favoring their binding and determinant to the inhibitory activity, though with no additive effect due to the presence of the sulfur atom. 

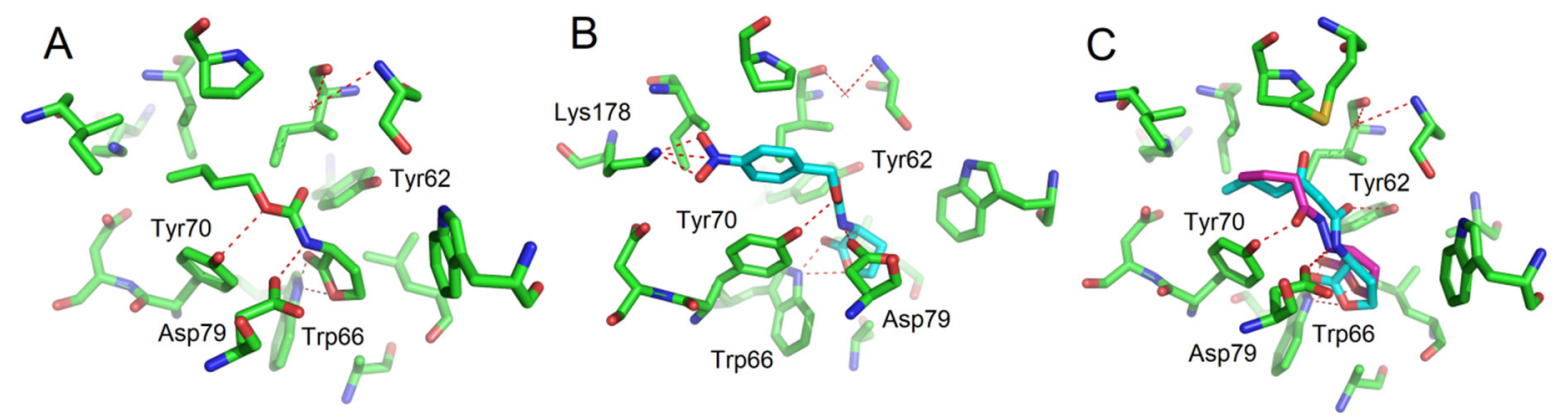

Figure 3. Proposed binding modes of compounds 2 (A) and 7 (B) within the binding site of the LuxR model obtained as a result of docking experiments. (C) Proposed binding modes of compound 12 (magenta) and OHHL (cyan) [30] obtained as a result of docking experiments. Hydrogen bonds are indicated in red dashes. Design of analogues of OHHL modified on the amide functional group.

For hydrazide analogues, all inactive, docking studies revealed that the carbonyl of the hydrazide group is involved in a hydrogen bond with Tyr70 but misses the interaction with Tyr62. Indeed, the $\mathrm{C}=\mathrm{O}$ is located opposite to where it is usually for natural ligands or other active analogues (Figure 3C).

Figure 3 compares the binding modes of the active carbamate 2 , the nitro compound 7 (the most active compound in the study), and the hydrazide 12 within the binding site of the LuxR model.

\section{Conclusions}

A novel family of carbamate/thiocarbamate analogues of AHLs was studied as quorum sensing modulators on the Vibrio fisheri system. Both agonistic and antagonistic activities were found depending on chain length and substitution. The binding mode within the LuxR binding site unveils a new hydrogen bond between the supplementary oxygen or sulfur atoms of all compounds with Tyr70, an important conserved residue in the LuxR family. The most active compounds are the $p$-nitro benzyl derivatives that exhibit additional interactions with Lys178. This study showed the ability of the carbamate/thiocarbamate functions to mimic the amide group of AHLs for fine-tuning QS modulation.

H NMR and 13C NMR data are available in Supplementary Materials.

Supplementary Materials: The following are available online at http://www.mdpi.com/2218-273X/10/3/455/s1, ${ }^{1} \mathrm{H}$ NMR and ${ }^{13} \mathrm{C}$ NMR data.

Author Contributions: Y.Q. and L.S. conceived and designed the experiments; Q.Z. performed the experiments; Y.Q. and L.S. analyzed the data; Q.Z., Y.Q., and L.S. wrote the paper. All authors have read and agreed to the published version of the manuscript.

Acknowledgments: The authors are grateful to CNRS and MESRI for financial support. They also thank Sylvie Reverchon and Elodie Kenck for helpful discussions regarding biological evaluation of QS modulators. Finally, Qiang Zhang thanks the China Scholarship Council program for a scholarship.

Conflicts of Interest: The authors declare no conflicts of interest.

\section{References}

1. Fuqua, C.; Greenberg, E.P. Self perception in bacteria: Quorum sensing with acylated homoserine lactones. Curr. Opin. Microbiol. 1998, 1, 183-189. [CrossRef]

2. Garg, N.; Manchanda, G.; Kumar, A. Bacterial quorum sensing: Circuits and applications. Antonie Van Leeuwenhoek 2014, 105, 289-305. [CrossRef] [PubMed]

3. Geske, G.D.; O’Neill, J.C.; Blackwell, H.E. Expanding dialogues: From natural autoinducers to non-natural analogues that modulate quorum sensing in Gram-negative bacteria. Chem. Soc. Rev. 2008, 37, 1432-1447. [CrossRef] [PubMed]

4. Papenfort, K.; Bassler, B.L. Quorum sensing signal-response systems in Gram-negative bacteria. Nat. Rev. Microbiol. 2016, 14, 576-588. [CrossRef] [PubMed]

5. Churchill, M.E.; Chen, L. Structural basis of acyl-homoserine lactone-dependent signaling. Chem. Rev. 2011, 111, 68-85. [CrossRef] 
6. Brackman, G.; Coenye, T. Quorum sensing inhibitors as anti-biofilm agents. Curr. Pharm. Des. 2015, $21,5-11$. [CrossRef]

7. Galloway, W.R.; Hodgkinson, J.T.; Bowden, S.D.; Welch, M.; Spring, D.R. Quorum sensing in Gram-negative bacteria: Small-molecule modulation of AHL and AI-2 quorum sensing pathways. Chem. Rev. 2011, 111, 28-67. [CrossRef]

8. LaSarre, B.; Federle, M.J. Exploiting quorum sensing to confuse bacterial pathogens. Microbiol. Mol. Biol. Rev. 2013, 77, 73-111. [CrossRef]

9. Reuter, K.; Steinbach, A.; Helms, V. Interfering with Bacterial Quorum Sensing. Perspect. Med. Chem. 2016, 8, 1-15. [CrossRef]

10. Stevens, A.M.; Queneau, Y.; Soulere, L.; von Bodman, S.; Doutheau, A. Mechanisms and synthetic modulators of AHL-dependent gene regulation. Chem. Rev. 2011, 111, 4-27. [CrossRef]

11. Tay, S.B.; Yew, W.S. Development of quorum-based anti-virulence therapeutics targeting Gram-negative bacterial pathogens. Int. J. Mol. Sci. 2013, 14, 16570-16599. [CrossRef] [PubMed]

12. Wang, Y.; Ma, S. Small molecules modulating AHL-based quorum sensing to attenuate bacteria virulence and biofilms as promising antimicrobial drugs. Curr. Med. Chem. 2014, 21, 296-311. [CrossRef] [PubMed]

13. Frezza, M.; Castang, S.; Estephane, J.; Soulere, L.; Deshayes, C.; Chantegrel, B.; Nasser, W.; Queneau, Y.; Reverchon, S.; Doutheau, A. Synthesis and biological evaluation of homoserine lactone derived ureas as antagonists of bacterial quorum sensing. Bioorg. Med. Chem. 2006, 14, 4781-4791. [CrossRef] [PubMed]

14. Frezza, M.; Soulere, L.; Reverchon, S.; Guiliani, N.; Jerez, C.; Queneau, Y.; Doutheau, A. Synthetic homoserine lactone-derived sulfonylureas as inhibitors of Vibrio fischeri quorum sensing regulator. Bioorg. Med. Chem. 2008, 16, 3550-3556. [CrossRef]

15. Castang, S.; Chantegrel, B.; Deshayes, C.; Dolmazon, R.; Gouet, P.; Haser, R.; Reverchon, S.; Nasser, W.; Hugouvieux-Cotte-Pattat, N.; Doutheau, A. N-Sulfonyl homoserine lactones as antagonists of bacterial quorum sensing. Bioorg. Med. Chem. Lett. 2004, 14, 5145-5149. [CrossRef]

16. Boukraa, M.; Sabbah, M.; Soulere, L.; El Efrit, M.L.; Queneau, Y.; Doutheau, A. AHL-dependent quorum sensing inhibition: Synthesis and biological evaluation of alpha-(N-alkyl-carboxamide)-gamma-butyrolactones and alpha-(N-alkyl-sulfonamide)-gamma-butyrolactones. Bioorg. Med. Chem. Lett. 2011, 21, 6876-6879. [CrossRef]

17. Sabbah, M.; Fontaine, F.; Grand, L.; Boukraa, M.; Efrit, M.L.; Doutheau, A.; Soulere, L.; Queneau, Y. Synthesis and biological evaluation of new $\mathrm{N}$-acyl-homoserine-lactone analogues, based on triazole and tetrazole scaffolds, acting as LuxR-dependent quorum sensing modulators. Bioorg. Med. Chem. 2012, 20, 4727-4736. [CrossRef]

18. Ghosh, A.K.; Brindisi, M. Organic carbamates in drug design and medicinal chemistry. J. Med. Chem. 2015, 58, 2895-2940. [CrossRef]

19. Zhu, J.; Beaber, J.W.; More, M.I.; Fuqua, C.; Eberhard, A.; Winans, S.C. Analogs of the autoinducer 3-oxooctanoyl-homoserine lactone strongly inhibit activity of the TraR protein of Agrobacterium tumefaciens. J. Bacteriol. 1998, 180, 5398-5405. [CrossRef]

20. Persson, T.; Hansen, T.H.; Rasmussen, T.B.; Skinderso, M.E.; Givskov, M.; Nielsen, J. Rational design and synthesis of new quorum-sensing inhibitors derived from acylated homoserine lactones and natural products from garlic. Org. Biomol. Chem. 2005, 3, 253-262. [CrossRef]

21. Uzar, H.C. Improved Synthesis of L-Homoserine Derivatives from L-Aspartic Acid. Synthesis 1991, 1991, 526-528. [CrossRef]

22. Lall, M.S.; Karvellas, C.; Vederas, J.C. Beta-lactones as a new class of cysteine proteinase inhibitors: Inhibition of hepatitis A virus 3C proteinase by N-Cbz-serine beta-lactone. Org. Lett. 1999, 1, 803-806. [CrossRef] [PubMed]

23. Warnecke, A.; Kratz, F. 2,4-bis(hydroxymethyl)aniline as a building block for oligomers with self-eliminating and multiple release properties. J. Org. Chem. 2008, 73, 1546-1552. [CrossRef] [PubMed]

24. Baldwin, J.E.; Adlington, R.M.; Moss, N. Synthetic Approaches to 2-Methoxycysteine containing Peptides. The conversion of [(5S)-5-amino-5-carboxy-2-oxapentanoyl]-2-methoxy-(2S)-cysteinyl-(2R)-valine into 10-Oxa-6 $\alpha$-methoxyisopenicillin N by the Enzyme Isopenicillin N Synthase. Tetrahedron 1989, 45, 2841-2856. [CrossRef]

25. Saha, A.; Kumar, R.; Devakumar, C. Development and assessment of green synthesis of hydrazides. Indian J. Chem. B 2010, 49, 526-531. 
26. Demange, L.; Boeglin, D.; Moulin, A.; Mousseaux, D.; Ryan, J.; Berge, G.; Gagne, D.; Heitz, A.; Perrissoud, D.; Locatelli, V.; et al. Synthesis and pharmacological in vitro and in vivo evaluations of novel triazole derivatives as ligands of the ghrelin receptor. 1. J. Med. Chem. 2007, 50, 1939-1957. [CrossRef]

27. Geske, G.D.; O’Neill, J.C.; Blackwell, H.E. N-phenylacetanoyl-L-homoserine lactones can strongly antagonize or superagonize quorum sensing in Vibrio fischeri. ACS Chem. Biol. 2007, 2, 315-319. [CrossRef]

28. Syrpas, M.; Ruysbergh, E.; Stevens, C.V.; De Kimpe, N.; Mangelinckx, S. Synthesis and biological evaluation of novel N-alpha-haloacylated homoserine lactones as quorum sensing modulators. Beilstein J. Org. Chem. 2014, 10, 2539-2549. [CrossRef]

29. Soulere, L.; Frezza, M.; Queneau, Y.; Doutheau, A. Exploring the active site of acyl homoserine lactones-dependent transcriptional regulators with bacterial quorum sensing modulators using molecular mechanics and docking studies. J. Mol. Graph. Model. 2007, 26, 581-590. [CrossRef]

30. Estephane, J.; Dauvergne, J.; Soulere, L.; Reverchon, S.; Queneau, Y.; Doutheau, A. N-Acyl-3-amino-5H-furanone derivatives as new inhibitors of LuxR-dependent quorum sensing: Synthesis, biological evaluation and binding mode study. Bioorg. Med. Chem. Lett. 2008, 18, 4321-4324. [CrossRef]

31. Soulere, L.; Queneau, Y. Conformational and docking studies of acyl homoserine lactones as a robust method to investigate bioactive conformations. Comput. Biol. Chem. 2019, 79, 48-54. [CrossRef] [PubMed]

32. Morris, G.M.; Goodsell, D.S.; Halliday, R.S.; Huey, R.; Hart, W.E.; Belew, R.K.; Olson, A.J. Automated Docking Using a Lamarckian Genetic Algorithm and an Empirical Binding Free Energy Function. J. Comput. Chem. 1998, 19, 1639-1662. [CrossRef]

33. Thompson, M.A. ArgusLaB Software, Version 4.0.1; Planetaria Software LLC: Seattle, WA, USA, 2004.

34. Rahmathullah, S.M.; Hall, J.E.; Bender, B.C.; McCurdy, D.R.; Tidwell, R.R.; Boykin, D.W. Prodrugs for amidines: Synthesis and anti-Pneumocystis carinii activity of carbamates of 2,5-bis(4-amidinophenyl)furan. J. Med. Chem. 1999, 42, 3994-4000. [CrossRef] [PubMed]

35. Reverchon, S.; Chantegrel, B.; Deshayes, C.; Doutheau, A.; Cotte-Pattat, N. New synthetic analogues of $\mathrm{N}$-acyl homoserine lactones as agonists or antagonists of transcriptional regulators involved in bacterial quorum sensing. Bioorg. Med. Chem. Lett. 2002, 12, 1153-1157. [CrossRef]

36. Li, S.Z.; Xu, R.; Ahmar, M.; Goux-Henry, C.; Queneau, Y.; Soulere, L. Influence of the d/l configuration of N-acyl-homoserine lactones (AHLs) and analogues on their Lux-R dependent quorum sensing activity. Bioorg. Chem. 2018, 77, 215-222. [CrossRef]

37. Gregoret, L.M.; Rader, S.D.; Fletterick, R.J.; Cohen, F.E. Hydrogen bonds involving sulfur atoms in proteins. Proteins 1991, 9, 99-107. [CrossRef]

38. Ahumedo, M.; Drosos, J.C.; Vivas-Reyes, R. Application of molecular docking and ONIOM methods for the description of interactions between anti-quorum sensing active (AHL) analogues and the Pseudomonas aeruginosa LasR binding site. Mol. Biosyst. 2014, 10, 1162-1171. [CrossRef] 